\title{
Effect of high fat ketogenic diet on some cardiovascular and renal parameters in Wistar albino rats
}

\author{
Eiya Bibiana OMOZEE* and Osakue James OSAMUYIMEN
}

\author{
Department of Physiology, School of Medical Sciences University of Benin, Benin City, Nigeria. \\ *Corresponding author; E-mail: eiyabibiana@gmail.com, Tel: +23708081953639
}

\begin{abstract}
Ketogenic diet is used in weight control. This study aimed at determining the effect of the consumption of this high fat, low carbohydrate diet on plasma viscosity, lipid profile, serum and urine creatinine, urea, electrolytes and urinary $\mathrm{pH}$. Forty Wistar rats grouped into experimental (A) and control groups (B) were used. Experimental group was fed with $65 \%$ fatty diet; control group was fed with normal rat chow for eight weeks. Fasting samples were collected at the end of the study for analysis. Biochemical analyses were done using spectrophotometric method, electrolytes were assayed by the ion electrode selective method, plasma viscosity was analysed using the Reid and Ugwu method and urinalysis strip was used to measure urinary $\mathrm{pH}$. A significant increase in serum $(0.866 \pm 0.031)$ and urinary $(5.470 \pm 0.424)$ creatinine urinary sodium (147.3 \pm 23.60$)$, chloride $(136.0 \pm 23.90)$, bicarbonate $(1570 \pm 1065)$ and $\mathrm{pH}(7.60 \pm 1.63)$ were observed in the experimental group when compared with serum values of control group $(0.6600 \pm 0.060)$ and urinary $(1.700 \pm 0.230)$ creatinine, sodium $(35.60 \pm 18.92)$, chloride $(30 \pm 17.05)$, bicarbonate $(800 \pm 184.4)$ and $\mathrm{pH}$

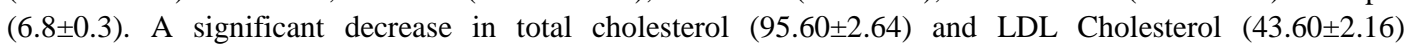
concentrations were observed in the experimental group when compared with the control group, total cholesterol (132.8 \pm 10.7$)$ and LDL Cholesterol (69.00 \pm 10.80$)$. This study also showed a significant increase in weight of control groups (initial weight $(\mathrm{g})$ 135.2 \pm 5.115 , final weight, 151.2 \pm 38.3 ) while there was no significant increase in weight of the experimental group (Initial weight 170.6 \pm 11.95 , final weight170.6 \pm 11.21 ). There was no significant difference in the other parameters when both groups were compared. These findings have clearly shown that intake of high fat ketogenic diet is not harmful to the heart, however the increase in serum creatinine in the experimental group could be as a result of the effect of the diet on the kidney or it could be due to muscle wastage which might be responsible for maintenance of their body weight. Increased urinary sodium excretion could lead to increased loss of fluid which can also give an impression of weight loss.
\end{abstract}

(C) 2018 International Formulae Group. All rights reserved.

Keywords: Ketogenic diet, Cardiovascular, Renal, plasma viscosity, lipid profile, electrolytes.

\section{INTRODUCTION}

Obesity is a major risk factor for most metabolic syndromes. Asa result, one of the treatment strategies is weight reduction. Weight loss is usually used as a means of therapy and it is aimed at improving some of the metabolic syndromes. In recent time, the use of ketogenic diet as a means of weight control has been on the increase. Ketogenic diet is characterized by a reduction in carbohydrates (usually less than $50 \mathrm{~g} /$ day) a relative moderate increase in protein and a 
high fat diet (Veech, 2004). This diet is based on consumption of long chain saturated triglycerides in a ratio of $3: 1$ or $4: 1$ with its derivation from fat consumption of about $90 \%$, this implies that majority of its calories is derived from fat (Kristopher et al., 2007). Ketogenic diets are of two types, the high fat ketogenic diet and high protein ketogenic diet. Long term consumption of Ketogenic diet has been successfully used in the treatment of refractory paediatric epilepsy, despite its likely side effect (Freeman et al., 2006). Researchers have shown that this diet is not only useful in weight control but also it has been shown to result in improvement of metabolic syndromes (Kennedy et al., 2001).

However the fact that a high fatty diet might have some detrimental effect on lipid profile, which might affect plasma viscosity of individuals on this diet and by implication, impairs cardiovascular functions should be of great concern.

Blood viscosity is the intrinsic resistance of blood to flow in blood vessels in which its major determinants are the volume fraction of red blood cells, plasma viscosity, fibrinogen and lipoprotein (Lowe et al., 1997). Studies report that for every kilogram of weight loss, high density lipoprotein (HDL) cholesterol increases by $0.009 \mathrm{mmol} / \mathrm{l}$ and triglycerides decrease by $0.015 \mathrm{mmol} / \mathrm{l}$ (Dattilo and Kris, 1992), Other studies also indicate that ketogenic diets results in significant decrease in serum triglycerides, small increase in total and low density lipoprotein (LDL) cholesterol and a moderate increase in high density lipoprotein (HDL) cholesterol in subjects with normal lipid profile (Hossein et al, 2006). Elevated fasting triglycerides is found to be an independent risk factor for cardiovascular disease (Austin et.al,1998), on the other hand numerous studies suggest that high carbohydrate diet raise triglycerides levels and reduce high density lipoprotein (HDL) cholesterol along with insulin resistance (Taubes, 2001; Zammit et al, 2001) and when carbohydrate was replaced with saturated fat the changes in triglycerides were evident, where high density lipoprotein (HDL) cholesterol levels increased drastically when compared to carbohydrate diet (Reaven, 2000; Krauss, 2001).

Very high levels of ketones make the blood more acidic and overburden the kidneys. One of the side effects of a ketogenic diet is the formation of kidney stones. In processing higher amounts of proteins, the kidneys work hard and are forced to excrete more sodium, calcium and potassium, as well as filter more of the bile products of protein metabolism. This extra fluid and electrolyte loss can cause low blood pressure, which is another function mediated by the kidneys. Ketosis in the presence of diabetes can lead to 'Ketoacidosis' and coma and can be life threatening.

Studies have shown that changing of diet from high carbohydrate low fat diet to high fat low carbohydrate diet resulted in a significant reduction in body weight, improved glycemic control and also led to a reversal of a six years long decline of renal function in patients with type 2 diabetes, (Jorgen et al., 2006). Electrolytes consumed by most people on a ketogenic diet is insufficient, some of the fatigue which was demonstrated in early ketogenic diet studies have been associated with insufficient mineral intake, especially sodium (Reid and Ugwu, 1987). A known effect of ketogenic diet is a decrease in blood pressure, most likely due to sodium excretion and water loss. In individuals with high blood pressure (hypertension), this may be beneficial. Individuals with normal blood pressure may suffer from 'orthostatic hypotension', which is a light-headedness which occurs when moving from a sitting to standing posture (De Haven et al., 1980). The inclusion of sufficient minerals appears to be able to prevent symptoms of fatigue, nausea and hypotension (Reid and Ugwu, 1987). To counteract the excretion of minerals on a ketogenic diet, additional mineral intake is required. An excessive intake of any single mineral (especially potassium) can be just as dangerous as a deficiency.

This study was therefore aimed at determining the effect of the consumption of this high fat, low carbohydrate diet on plasma 
viscosity, lipid profile, serum and urine creatinine, urea, electrolytes and urinary $\mathrm{pH}$ with a view to ascertain its safety on renal and cardiovascular system.

\section{MATERIALS AND METHODS Experimental design}

Forty (40) albino Wistar rats of either sex were obtained from the pharmacology animal house, faculty of pharmacy university of Benin. The rats were also housed in the same pharmacology animal house for the duration of the study. The rats were weighed on arrival and then acclimatized for a period of two week. During this period they were fed on the normal rat chow having free access to feeds and water. At the end of acclimatization the animals were grouped into two, group A (20) experimental group and group B (20) control group. The experimental group was fed with $65 \%$ saturated fat ketogenic diet, while the control group was fed the normal rat chow. Both groups were on the diet for 30 days and they were allowed free access to feeds and water during the duration of the experiment.

\section{Collection of sample}

Twenty-four hours fasted blood and urine samples were collected for electrolytes, and serum creatinine analysis as well as lipid profile and blood viscosity analysis. The rats were put in metabolic cages for collection of 24 hour urine sample. The rats were put to sleep using chloroform in a closed chamber. Blood samples were collected from the abdominal aorta and cardiac puncture into plain tubes and EDTA container.

\section{Biochemical analysis}

All the biochemical analysis was done spectrophotometrically using Randox reagent kit. Plasma viscosity was measured by Reid and Ugwu method.

\section{Diet formulation}

The experimental group was fed the $65 \%$ fatty diet for a period of 3 weeks.

\section{Determination of plasma viscosity}

Reid and Ugwu (1987) method was used to determine the relative plasma viscosity.

\section{Principle:}

This procedure is carried out based on comparison of flow rate of plasma and distilled water under equal pressure and constant temperature and result expressed as plasma viscosity of plasma relative to that of water.

\section{Determination of lipid profile}

Total Serum Cholesterol was analyzed using the method of Allain (1974) while HDL was analyzed using the method of Lopes (1977). Serum triglyceride was determined by the enzymatic method of Stein, (1987). LDL was extrapolated from total cholesterol, triglyceride and HDL by the method of Friedwald (1972). The estimation of electrolytes was carried out using an ionselective electrode 4000 (ISE 4000) (Külpmann and Wien, 1992). Creatinine was assayed by two point's kinetic, modified Jafee increasing reaction by Bartels and Bolumer (1972). Serum and urine urea were determined by Berthelot method (Newman and Price 2001). Urine $\mathrm{pH}$ was determined using reagent strip by Free et al. (1957).

All biochemical assays were carried out in the Clinical Chemistry laboratory of University of Benin Teaching Hospital. Blood viscosity was carried in Physiology Laboratory, University of Benin.

\section{Statistical analysis}

Data are presented as mean \pm standard error of mean (SEM). Student $t$ test was used for the comparison between experimental and control groups. $\mathrm{P}<0.05$ was considered statistically significance. The Graph pad prism version 5.0 statistical package was used for the result analysis.

\section{RESULTS}

Table 2 compares the mean values of the lipid profile and plasma viscosity following treatment with ketogenic diet in Wistar rats. 
There was a significant $\quad(\mathrm{P}<0.05)$ reduction in total cholesterol concentration of experimental when compared with the control group. Plasma viscosity, HDL cholesterol and triglycerides values did not show any significant difference when control groups were compared with the experimental groups. However, there was a significant reduction in concentrations of LDL cholesterol concentration of experimental groups when compared with the control groups

Table 3 compares the mean values of serum electrolytes, creatinine, and urea and body weight following treatment with ketogenic diet on Wistar rats.

There was a significant $(\mathrm{P}<0.05)$ increase in serum creatinine concentrations of the experimental group when compared with the control group. However, values of serum sodium, chloride, potassium and bicarbonate did not show any significant difference when experimental groups were compared with the control group. There was a significant $(\mathrm{P}<0.05)$ increase in the initial weight of the control group when compared the final weight, while the initial weight of the experimental group did not show any significant difference with the final weight.

Table 4 compares the mean values of urine electrolytes, creatinine, urea and urine $\mathrm{pH}$ following treatment with ketogenic diet on Wistar rats.

There was a significant $(\mathrm{P}<0.05)$ increase in urinary excretion of sodium, bicarbonate, chloride and creatinine in the experimental groups when compared with control group. Our results also showed a significant $(\mathrm{P}<0.05)$ increase in urinary $\mathrm{pH}$ of the experimental group when it was compared with the control group. There was however no significant difference in urinary excretion of potassium and urea when control and experimental values were compared.

Table 1: Percent composition of experimental diet.

\begin{tabular}{lll}
\hline Constituents & $\begin{array}{l}\text { Control } \\
\text { (B) }\end{array}$ & $\begin{array}{l}\text { Experimental } \\
\text { (A) }\end{array}$ \\
\hline Coconut Flour & - & $\mathbf{1 5}$ \\
Maize & 70 & - \\
Butter & 10 & $\mathbf{6 5}$ \\
Fish Meal & 15 & $\mathbf{1 5}$ \\
Bone Meal & 2 & $\mathbf{2}$ \\
Limestone & 1 & $\mathbf{1}$ \\
Salt & 0.5 & $\mathbf{0 . 5}$ \\
Vit-Min Premix & 0.5 & $\mathbf{0 . 5}$ \\
Lysine & 0.3 & $\mathbf{0 . 3}$ \\
Meth \&Cys & 0.3 & $\mathbf{0 . 3}$ \\
\end{tabular}

Table 2: The mean values of the lipid profile and plasma viscosity following Treatment with ketogenic diet in Wistar rats.

\begin{tabular}{llll}
\hline Lipid Profile & Control & Experimental & P-Values \\
\hline $\begin{array}{l}\text { Total cholesterol } \\
(\mathrm{mg} / \mathrm{dl})\end{array}$ & $132.8 \pm 10.77$ & $95.60 \pm 2.64^{*}$ & 0.0006 \\
Triglyceride $(\mathrm{mg} / \mathrm{dl})$ & $88.20 \pm 17.62$ & $94.90 \pm 4.67$ & 0.6337
\end{tabular}



HDL (mg/dl)
$36.20 \pm 2.33$
$33.20 \pm 1.66$
0.3146
LDL (mg/dl)
$69.00 \pm 10.80$
$43.60 \pm 2.16^{*}$
0.0072
Plasma Viscosity
$1.478 \pm 0.064$
$1.426 \pm 0.054$
0.5712

$* \mathrm{P}<0.05$ indicates significant difference when control is compared with experimental group.

Table 3: The mean values of serum electrolytes, creatinine, urea and body weight following treatment with ketogenic diet on Wistar rats.

\begin{tabular}{llll}
\hline Parameters & Control & Experimental & P-values \\
\hline $\begin{array}{l}\text { Serum sodium } \\
(\mathrm{mMol} / \mathrm{L})\end{array}$ & $143.2 \pm 1.655$ & $143.4 \pm 1.077$ & 0.9185 \\
$\begin{array}{l}\text { Serum potassium } \\
(\mathrm{mMol} / \mathrm{L})\end{array}$ & $8.160 \pm 0.628$ & $7.970 \pm 0.331$ & 0.7712 \\
$\begin{array}{l}\text { Plasma bicarbonate } \\
(\mathrm{mMol} / \mathrm{L})\end{array}$ & $22.20 \pm 0.860$ & $23.20 \pm 0.489$ & 0.2950 \\
$\begin{array}{l}\text { Serum chloride ion } \\
(\mathrm{mMol} / \mathrm{L})\end{array}$ & $109.6 \pm 1.470$ & $110.6 \pm 0.792$ & 0.5210 \\
$\begin{array}{l}\text { Plasma urea }(\mathrm{mg} / \mathrm{dl}) \\
\text { Initial Weight }(\mathrm{g})\end{array}$ & $48.80 \pm 2.67$ & $57.10 \pm 4.476$ & 0.2374 \\
Final weight $(\mathrm{g})$ & $135.2 \pm 5.115$ & $170.6 \pm 11.95$ & $<0.0001$ \\
\hline
\end{tabular}

$* \mathrm{P}<0.05$ indicates significant difference when control is compared with experimental group.

Table 4: The mean values of urine electrolytes, creatinine, urea and urine $\mathrm{pH}$ following treatment with ketogenic diet on Wistar rats.

\begin{tabular}{llll}
\hline Parameters & Control & Experimental & P-Values \\
\hline Urine sodium $(\mathrm{mMol} / \mathrm{L})$ & $35.60 \pm 18.92$ & $147.3 \pm 23.60^{*}$ & 0.0089 \\
Urine potassium $(\mathrm{mMol} / \mathrm{L})$ & $36.24 \pm 18.29$ & $59.55 \pm 8.058$ & 0.1937 \\
& & & \\
Urine bicarbonate (mMol/L) & $800.0 \pm 184.4$ & $1570 \pm 106.5^{*}$ & 0.0019 \\
Urine creatinine $(\mathrm{mg} / \mathrm{dl})$ & $1.700 \pm 0.230$ & $5.470 \pm 0.424^{*}$ & $<0.0001$ \\
Urine chloride $(\mathrm{mMol} / \mathrm{L})$ & $30.00 \pm 17.05$ & $136.0 \pm 23.97^{*}$ & 0.0122 \\
Urine Urea $(\mathrm{mg} / \mathrm{dl})$ & $264.6 \pm 7.76$ & $265.7 \pm 7.99$ & 0.9321 \\
Urine $\mathrm{pH}$ & & & \\
\hline
\end{tabular}

$* \mathrm{P}<0.05$ indicates significant difference when control is compared with experimental group. 


\section{DISCUSSION}

In this study, there was a significant reduction in total cholesterol concentrations level in rats fed with the high fat ketogenic diet when compared with the control group. This is in agreement with the findings of Paoli et al. (2010), and Heisset al. (2002) who reported a significant reduction in total cholesterol concentration and an increase in high density lipoprotein cholesterol (HDL-C) levels. There was however no significant difference in the high density lipoprotein cholesterol (HDL-C) levels between the experimental group and the control group when compared. Elevation of HDL-C concentration is very vital and helps in the reduction of coronary heart diseases (Eric et al., 2005 and Paoli et al., 2013).

There was no significant difference in the triglyceride level between the experimental group and the control group when compared. The low-carbohydrate ketogenic diet has also shown to particularly affect the level of blood triglycerides (Hussein et al., 2004; Borge et al., 2014). There are also significant positive effects on total cholesterol reduction and increase in high- density lipoprotein (Hussein et al., 2004; Hossein et al., 2006; Paoli et al., 2010).

Increase in triglyceride concentrations is strongly associated with low concentration of HDL-C. Triglyceride forms a major component of the skin oil (Paoli et al., 2013); hence a longer time might be required for any factor that can influence the body triglyceride concentration to affect blood parameters.

Findings in this study showed a significant reduction in low density lipoprotein cholesterol (LDL-C) levels of the experimental group when compared with the control group. This is in line with the findings of Eric et al., (2005), who observed a significant reduction in low density lipoprotein particle (LDL-P) concentrations after feeding their subjects with high fat ketogenic diet. In their study they observed a greater increase in large LDL and greater reduction in medium LDL. The reduction in LDL-C observed in our study in rats fed the ketogenic diet shows that the use of this diet can be favorable to individuals who have cardiovascular diseases since this diet tend to reduce LDL-C, elevation of LDL-C predisposes an individual to cardiovascular disease (Borge et al., 2014).

Values of plasma viscosity of control and experimental did not show any significant difference. The fact that the plasma viscosity of the experimental group did not increase even with the high fatty diet can be attributed to the values of LDL cholesterol which decreased in the experimental group. A relationship between LDL cholesterol and plasma viscosity has been reported by James and Robert (1998), according to their findings, a decrease in LDL cholesterol leads to a decrease in fibrinogen concentration as a result a decrease in plasma fibrinogen concentration which is a major determinant of plasma viscosity.

There was also a significant reduction in the weight of rats on the ketogenic diet after about 2 weeks intake of the diet, This is in agreement with the findings of Hossein et al. (2006) who reported a decrease in weight and corresponding reduction of total lipid profile but increase in HDL cholesterol. Westerp (2009), also reported weight reduction after intake of high fat ketogenic diet and attributed the reduction in weight to a decrease in calorie intake due to increased satiety level. Paoli (2013) also reported a reduction in weight; however the mechanism of weight reduction remains unclear.

Serum electrolyte concentrations showed no significant change in sodium, potassium, chloride and bicarbonate ions when compared with the control group. This is in agreement with the work of Henrietta and Olumese (2010), who reported no significant difference in serum electrolyte level after the intake of ketogenic diet.

In this study, we observed a significant increase in serum creatinine concentrations of the experimental group when compared with the control group. Serum creatinine concentration is a useful determinant in the determination of renal disease, according to Sidney and Shreeran (1997), an increase in serum creatinine level from the first value to a 
high value is an indicator of underlying renal failure.

Creatinine is a breakdown product of creatine phosphate in muscles, and is usually produced at a fairly constant rate by the body depending on muscle mass (Yuegang and Chengjun, 2008). However, in this study, the experimental groups were not adding weight probably building muscles hence, the increase in serum creatinine levels. The increase in serum creatinine observed in this study could be attributed to an increase in muscle mass. These findings are in accordance with the findings of Alessandra et al., (2008), who reported that creatinine excretion is also influenced by muscle mass, because creatinine formation occurs almost exclusively in the muscle. These findings further corroborate that intense physical activity directly influences body composition, reducing the body fat and increasing the fat-free mass. This also agrees with the findings of Sapna et al. (2012), who reported that in both health and disease, under steady state, serum creatinine can serve as a reliable muscle mass biomarker if appropriate adjustment for full or residual kidney function and dietary meat intake is undertaken.

The result from this study also showed that urinary electrolyte concentration showed a significant increase in sodium, bicarbonate and chloride ions when compared with control and no significant difference in potassium when compared with control. Electrolytes are charged particles in body fluids that helps transmit electrical impulses for proper nerve, heart and muscle impulses (Keeet al., 2004). Sodium and chloride, the components of table salt, are mostly concentrated outside the cells, while potassium is more concentrated inside the cells. The balance of these electrolytes on either side of the cell membrane not only allows electrical currents to pass between cells but also helps maintain the proper fluid balance in the tissues. Studies have shown that electrolytes consumed by most people on ketogenic diet is insufficient Phinney (1991) reported fatigue which is demonstrated in early ketogenic diet may be due to insufficient mineral intake especially sodium.
Urinary creatinine concentration showed that there was a significant increase compared to control group. Creatinine is a nitrogenous waste present in urine. Thus, an increase in muscle mass will lead to an increase in creatinine production and excretion. Urea value showed no significant change also indicating a normal kidney function. The urine $\mathrm{pH}$ showed a significant increase in the experimental when compared to control this can be attributed to increased excretion of bicarbonate in urine; this also agrees with study by Eiya and Obika (2016), in their study, they observed a significant increase in urinary $\mathrm{pH}$ after intake of high casein diet.

\section{Conclusion}

Findings from this study has clearly shown that intake of high fat ketogenic diet is not harmful to the heart due to the effect of this diet on LDL and HDL cholesterol as well as total cholesterol. Even though we did not observe any significant reduction in triglyceride values, the fact that there was no significant increase between triglyceride values of control and the experimental group is something worth noting, knowing that triglyceride makes the skin fat and hence longer time is required before its blood parameters can be affected. The fact that this diet did not result in weight gain shows that this diet can also be protective against most of the metabolic syndromes since obesity has been reported to be a predisposing factor to most metabolic syndromes. The increase in serum creatinine observed in this study could be attributed to increase in muscle mass in rats fed the ketogenic diet. However, there is need to carry out further study to ascertain the actual cause of the increase in serum creatinine.

\section{COMPETING INTERESTS}

The authors declare that they have no competing interests.

\section{AUTHORS' CONTRIBUTIONS}

EBO conceived the idea for the work and wrote the proposal; OJO assisted in the 
technical aspect of this study and in editing the manuscript. Both parties gave final approval to the manuscript.

\section{ACKNOWLEDGEMENTS}

We will like to appreciate members of staff in the animal house for assisting in caring for the animals in the course of the study.

\section{REFERENCES}

Alessandra CB, Marion SA, Natalia CM, Viviane BM, Aparecido BP, Gianni MK, Ita PH. 2008. Influence of Muscle Mass and Physical Activity on Serum and Urinary Creatinine and Serum Cystatin C. Clin J Am SocNephrol, 3(2): 348-354. DOI:

http://doi.org/10.2215/CJN.02870707//d oi.org/10.2215/CJN.02870707

Allain CC, Poon LS, Chan CS, Richmond W, Fu PC. 1974. Enzymatic assay of Total Cholesterol. Clin. Chem. 20: 470.

Austin MA, Hokanson JE, Edwards KL. 1998. Hypertriglyceridemia as a cardiovascular risk factor. Americal Journal of Cardiology, 81: 7-12. DOI: 17925/USE.2006.00.1.6

Bartels H, Bolumer M. 1972. Serum creatinine determination without protein Precipitation. Clin. Chem. Accta. 37: 193-197.

Borge G, Nordestgaard, Annette Varbo. 2014. Lipids and cardiovascular disease: triglycerides. Cardiovascular Disease, Series 384: 626-635. DOI: https://doi.org/10.1016/S01406736 (14)61177-

Dattilo AM, Kris PM. 1992. Effects of weight reduction on blood lipids and lipoprotein: a meta-analysis. American Journal of Clinical Nutrition, 56: 320328. DOI : 1093/ajcn/56.2.320.

DeHaven J, Sherwin R, Hendler R, Felig P. 1980. Nitrogen and sodium balance and sympathetic-nervous-system activity in obese subjects treated with a low-calorie protein or mixed diet. $N$ Engl $\mathrm{J}$ Med., 302(9): $477-482 . \quad$ DOI: 10 1056/NEM198002283020901

Eric C, William S, YancyJr, Maren K, Tera Dudley, John R, Guyton. 2005. Effect of a low-carbohydrate, ketogenic diet program compares to low-fat diet on fasting lipoprotein subclasses. International Journal of Cardiology, 110: 212-216. DOI :10.1016lj.ijcard2005.08.034

Eiya BO, Obika LFO. 2016. Effects of high plant cowpeas (VIGNA UNGUCULATA) and animal (casein) protein intake on some serum and urinary electrolytes concentrations in rats. Annals of Biomedical Sciences. 15: 41-65.

Free AH, Rupe CO, Metzler T. 1957. Urinalysis strip. Clin Chem., 3: 716. DOI: 10:.1530/cma.61590

Freeman J, Veggiatti P, Lanzi G, Tagliabue A, Perucca E. 2006. The ketogenic diet: from molecular mechanisms to clinical effects. Epilepsy Reserve, 68: 123-125. DOI: 10.1016/eplepsyres2005.10.003

Frierdewald WT, Levy RL, Fredrickson DS. 1972. Estimation of the concentration of low-density lipoprotein cholesterol in plasma without use of the preparative ultracentrifuge. Clinical Chemistry, 18: 499. DOI: 10.5963/LSMR0402002

Heiss G, Johnson N, Reiland S, Davis CE, Tyroler HA. 1980. The epidemiology of plasma high density lipoprotein cholesterol levels. The Lipid Research Clinics Program Prevalence Study; summary. Circulation. 62: 116-136.

Henrietta O, Olumese EF. 2010. Effect of low carbohydrate high fat Nigerian-like dieton biochemical indices in rabbits. Pakistan Journal of Nutrition, 9(3): 245249. DOI: $10.3923 /$ pjn.2008.640.644

Hossein K, Ali E, Mansour R, Mazaher R, Behnaz N, Reza K. 2016. Serum lipid profile and clinical characteristics of 
patients with xanthelasmapalpebrarum. Anais Brasileiros de Dermatologia, 91 (4): 468-471. DOI: 10.1590/abd18064841.20164607

James HS, Robert SR. 1998. Treatment of severe hypertriglyceridemia lowers plasma viscosity. Artheroslerosis. 137: 401-405.

Jorgen VN. Per Westerlund and Per Bygren 2006. A low-carbohydrate diet may prevent end stage renal failure in type 2 diabetes. A case report. NutrMetab, 3(23): 1-6. DOI: $10.1186 / 1743-7075-3-$ 23

Kee J, Paulanka B, Purnel L. 2004. Fluids and electrolytes with clinical application: a programmed approach. Clifton Park, N.Y Delmar learning.

Kennedy SR. Bickerdike R. Berge RK. Dick JR, Tochera DR. 2001. Influence of conjugated linoleic acid (CLA) or tetradecylthioacetic acid (TTA) on growth, lipid composition, fatty acid metabolisim and lipid gene expression of rainbow trout. Lipids, 43: 3-5.

Krauss RM. 2001. Atherogenic lipoprotein phenotype and diet-gene interactions. Journal of Nutrition, 131: 340-342. DOI: 10.1093/jn/131.2.340S

Kristopher J, Jong M. Rho. 2007. Anticonvulsant mechanisms of the ketogenic diet. Epilepsia. 48 (1): 43-58. DOI: 10.1111/j.1528-1167.2007.00915.x

Külpmann WR, Wien KW. 1992. Determination of electrolytes in serum and plasma. Suppl., 192: 37-41.

Lopes-Virella MF. 1977. Cholesterol determination in High-density Lipoproteins separated by three different methods. Clinical Chemistry, 23: 882.

Lowe GDO, Smith WC, Tunstall-Pedoe H, Crombie IK, Lennie SE, Anderson J, Barbenol JC. 1997. Cardiovascular risk and Heamorheology. Results from the Scottish Heart study and the MONICA-
Project, Glasgow. Clinical

Heamorheology, 8: 517-524.

Newman DJ, Price CP. 2001. Renal function, Tietz Fundamentals of Clinical Chemistry ( $5^{\text {th }}$ edn), Carl A, Burtis, Edward R, Ashwood (eds). W.B. Saunders: Philadephia; 698-912.

Paoli A, Rubini A, Volek JS, Grimaldi KA, 2013. Beyond the weight loss: Review of the therapeutic uses of very- lowcarbohydrate. Journal of Clinical NutritionI, 67: 789-796. DOI: 10.1038/ejen.2013.116

Paoli A, Cencil L, Fancelli M, Parmagnanui A, Fratter A, Cucchi A. 2011. Ketogenic diet andphytoextractscomparision of the efficacy of Mediterranean zone and tisanoreica diet on some health risk factors. Agro-Food Industry High Technology, 21: $24 . \quad$ DOI: 10.1186/1475-2891-10-112

Phinney SD, Horton ES, Sims EAH, Hanson J, Danforth E, Lagrange BM. 1991. Capacity for moderate exercise in obese subjects after adaptation to a hypocaloricketogenic diet. J. Clin. Invest., 66: 1152-1161. DOI: 10.1172/JCI109945

Reaven GM. 2000. Diet and syndrome X. Curr Atheroscler Rep. 2: 503-507. DOI: https://doi.org/10.1007/s11883-0000050-z

Reid HL, Ugwu AC. 1987. A simple technique for rapid determination of plasma viscosity. Nigerian Journal of Physiological Science, 3: 457-458.

Sapna SP, Miklos ZM, John AT, Joachim HI, Nazanin N, Deborah BS, Joel DK, Steven H, Saba PK, and Kamyar KZ. 2012. Serum creatinine as a marker of muscle mass in chronic kidney disease. J Cachexia Sarcopenia Muscle, 4(1): 19-29. DOI: 10.1007/s13539-0120079-1

Sidney KD, Shreeram A. 1997. Preventing progression and complications of renal 
disease. Hospital medicine, 33 (11): 1112.

Stein EA. 1987. Lipids, Lipoprotein and Apolipoprotein In Fundamentals of Clinical Chemistry (3rd edn), Tietz NW (ed). WB Saunders: Philadelphia. 478479.

Taubes. 2001. Nutrition: the soft science of dietary fat. Science, 291: 2536-2545. DOI: 10.1126/science.291.5513.2536

Veech RH. 2004. The therapeutic implications of ketone bodies the effects of ketone bodies in pathological conditions: ketosis, ketogenic diet, redox states, insulin resistance and mitochondrial metabolism. Prostaglandins Leukat Essential Fatty acids, 70: 309-319. DOI: 10.1016/j.plefa.2003.09.007

Westerp MS, Nieuwenhuizen A, Tome D, Soenen S, Westerterp KR. 2009. Dietary protein, weight loss, and weight maintenance. Annual Review Nutrition, 29: 21-41. DOI: 10.1146/annurev-nutr080508-141056

Yuegang Z, Chengjun W. 2008. Simultaneous Determination of Creatinine and Uric Acid In Human Urine by High Performance Liquid Chromatography. Anal Sci., 24: 15891592.

DOI: https://doi.org/10.2116/analsci.24.1589

McKay G. 2001. Insulin of hepatic triacylglycerol secreation and the etiology of insulin resistance. Journal Nutrition, 131: 2074-2077. DOI: 10.1093/jn/131.8.2074. 